\title{
Exploring discourse-based organizational change in Japan: practicing between dominant and alternative discourses
}

\author{
Makoto Nagaishi ${ }^{1}$ (D)
}

Received: 9 July 2021 / Accepted: 15 December 2021 / Published online: 13 January 2022

(C) The Author(s) 2022

\begin{abstract}
The primary objective of this study is to respond to Grant and Marshak's (J Appl Behav Sci 47:204-235, 2011) call for a move toward change perspectives that emphasize the generative nature of discourses, narratives, and conversations and how change practitioners discursively facilitate emergent processes. This article attempts to explore the question, "Can we specify the conditions and sources which make generative conversations emerge and may lead to a successful change effort in Japan?" The abductive inquiry into the question indicates that the generative change process convinces change sponsors that changing the dominant discourses and welcoming alternative ones can lead to the long-term development of the organization and the members. With respect to the sources of alternative discourses, psychological safety and trust in the external authority figure are generally required. The importance of survival anxiety and talent diversity may vary across the broad contexts on which organizations depend.
\end{abstract}

Keywords Discourse-based organizational change $\cdot$ Japanese cultural beliefs . Dominant discourse $\cdot$ Alternative discourse $\cdot$ Power process $\cdot$ Sense censoring

\section{Introduction}

Over the last two decades or so, the research in organization development and change (ODC) has experienced increasing interest in the nature of discoursebased organizational change (e.g.,Ford and Ford 1995; Grant and Marshak 2011; Marshak et al. 2000; Marshak and Grant 2008). This article responds to Grant and Marshak's (2011) call to move away from planned and deterministic change models toward an interpretive orientation that emphasizes emergent processes to invite generative discourses. It is interesting to analyze the cases of organizational change

Makoto Nagaishi

mnagaisi@mecl.chukyo-u.ac.jp

1 School of Global Studies, Chukyo University, 101-2 Yagoto-Honmachi, Showa-ku,

Nagoya 466-8666, Japan 
in Japan, where people have a cultural inclination to respect strong hierarchies and authority figures that shape dominant discourses in organizations. With an abductive approach, the present study explores whether we can specify the conditions and sources that result in generative conversations and may lead to a successful change effort in Japan. Namely, this study intends to fill the research gap to make the literature more grounded on data in a certain cultural setting.

The article is structured as follows. The following section deals with the review of literature in the studies of Japanese organizational culture and discourse-based organizational change. It is closely related to the application of the linguistic turn in social sciences, for which there is a growing body of literature in organization studies. The third section focuses on four dominant cultural beliefs in Japanese organizations. It attempts to analyze the possibility of the coexistence of good and bad fits between the beliefs and key discourse-based organizing assumptions. In the fourth section, the methodology is outlined, and some fundamental research questions are framed. The fifth section provides a detailed analysis of organizational discourse and change, focusing on the author's field studies in Japanese companies. The sixth section introduces some implications of these case studies. It suggests that the generative nature of the change process emerges when change sponsors buy in the proposition that changing the dominant discourses and welcoming alternative ones can lead to the long-term development of the organizations and themselves. The final section provides some concluding remarks and scope for future research.

\section{Japanese cultural beliefs and discourse-based change assumptions}

\section{Japanese cultural beliefs}

Eshun Hamaguchi (1982), who contrasts Japanese socio-cultural characteristics with Western ones, has further developed Hsu's $(1963,1971)$ line of research for understanding the concept of human relationships in Japan. He names the Japanese socio-cultural model "Contextualism." Its characteristics are (a) mutual dependence (human being cannot, in essence, live independently in a society), (b) mutual trust (interdependency can be natural only if a relationship is trustworthy), and (c) interpersonal relations as an end (sustaining a good relationship is not a means for an individual's survival but an end in itself for social life). At this point, it may be helpful to explain some crucial aspects of the Japanese societal culture in connection with the formalized Japanese Contextualism mentioned above.

\section{High-context communication}

As a critical cultural differentiator, high-context and low-context communication styles (Hall 1976) are widely accepted and empirically examined in the research on cross-cultural management (Aslani et al. 2016; Hofstede 2001; Hofstede and Bond 1988; Jaeger 1986). According to Meyer (2014, p 39), a high-context communication society believes that "good communication is sophisticated, nuanced, and layered. Messages are both spoken and read between the lines. Messages are often 
implied but not plainly expressed." Recent cross-cultural studies also point out that Japan has the distinction of being the highest-context culture in the world (Adair et al. 2015; Barkema et al. 2015; Meyer 2014; Szkudlarek et al. 2020).

LaCour's (2016) essential learning from his visit to Japan was his understanding of a Japanese aphorism "ichi ieba ju wakaru," which means "(f)rom the speaker's articulated $10 \%$, the listener should deduce the other $90 \%$," and this "illustrates an acculturated non-verbal communication pattern actualized in a shared context between speaker-listener" (LaCour 2016, p 66). Some Japanese communication patterns (e.g., "Read carefully between the lines of my writings" and "Understand my intention without asking me") frequently delivered by bosses to subordinates are notable examples of their preference for high-context communication styles.

One explanation for the Japanese orientation to high-context communication is the insularity and reliance on highly interdependent rice cultivation, which has built strict in-group cultural norms. According to these norms, both rewards and punishments are based on the level of assimilation in dominant narratives and contexts. This assimilation pressure is called "harmony orientation," which means avoiding confrontation and disruption is appropriate to sustain a good relationship at the workplace. From the viewpoint of leadership, the harmony orientation of both Japanese leaders and followers often induces a strong disinclination to deviate from the status quo in their organizational life (Nagaishi 2014).

\section{Company as family-tie pressure}

Intense pressures to be loyal and attached to groups/organizations are the characteristics of Japanese society (Keys and Miller 1984; Ouchi 1981). Some researchers argue that Japanese business leaders have utilized the Japanese cultural heritage of strong family-tie pressures to force collective discipline to promote company performance (Doi 1989; Keys and Miller 1984; Tanaka 1981; Trompenaars and Woolliams 2003). As Keys and Miller (1984, pp 347-348) point out, “(b)ecause the company becomes a surrogate for the family, work takes on the same ethos as a contribution to the family-loyalty, sincerity, and so on. The company's (family's) prosperity becomes more important than individual prosperity, and work for the company (not leisure) becomes the essence of life." Besides, it is traditionally believed that a father is an authority figure in the Japanese family who decides what is right.

This orientation has various organizational implications in Japan. Firstly, the Japanese managers eagerly inspire their followers to go beyond their self-interests to benefit the larger group. Secondly, Japanese managers tend to regard their team members as their children and raise and motivate them from a long-term perspective. In return, members are expected to practice filial piety and be loyal to their managers. This cultural norm, combined with the impacts of the Confucian philosophy (Marshak 1993a) and the Buddhist religious foundation (Teranishi 2018), leads to the long-term perspective among the Japanese to respect gradual and continuous development of processes and human beings. Thirdly, the idolization of "fatheras-an-authority figure" has been recast into Japanese high power-distance culture 
(Hofstede 2001), and the authoritarian pressure leads members to hide or restrict their judgments. ${ }^{1}$

\section{Discourse-based organizational change}

Some researchers who are interested in delineating the dynamics of generative change in organizations rely heavily upon a discourse-based approach derived from literature on organizational communication (Clark and Geppert 2011; Grant and Marshak 2011; Heracleous and Barrett 2001; Whittle et al. 2016). In this section, some working definitions of the key concepts have been provided to convey how they should be understood in the context of the discourse-based organizational change approach on which the author's analytical framework relies. The definitions are drawn from relevant social science literature, specifically in the fields of ODC and Japanese organizational culture.

\section{Grant and Marshak's (2011) seven dimensions of discourse-based organizational change}

Grant and Marshak's (2011) study is a seminal contribution to the subject of discourse-based organizational change. They have advanced an analytic framework explaining how discourse and organizational change are mutually implicated from an interpretivist orientation. Based on the core premise that organizational change is created and sustained through discourse, they summarize the following seven basic assumptions about organizing and leading the discursive change processes.

- (DOC1) Discourse is constructive; changing the dominant discourse leads to change.

- (DOC2) There are multiple levels of linked discourses influencing change.

- (DOC3) Change narratives are constructed and disseminated via conversations.

- (DOC4) Power processes shape the dominant discourse about change.

- (DOC5) Alternative discourses exist and may be drawn upon.

- (DOC6) Reflexivity increases the efficacy of the discourses used by change agents and researchers.

- (DOC7) Change discourses emerge from a continuous, iterative, and recursive process.

These interrelated dimensions suggest "how things are framed and talked about becomes a significant context that shapes how change agents, affected employees, and other stakeholders think about and respond to a change related issue or

\footnotetext{
1 Hofstede (1980, 2001) advances a pioneering dimensional framework for characterizing cultures. His framework and findings dominate current international management studies. He addresses five cultural dimensions: (a) power distance, which concerns social inequality and relations with authority; (b) uncertainty avoidance, which concerns cultural preferences for dealing with uncertainty; (c) individualismcollectivism, which refers to the strength of the ties that people have with others within their community; (d) masculinity-femininity, which concerns the social implications of gender-linked behavior; (e) longterm/short-term orientation, which shows the relative importance of the future.
} 
situation, or even the possibility of change itself' (Grant and Marshak 2011, p 207). The framework reveals some crucial practical insights into how discursive processes (e.g., storytelling and conversations) might increase the likelihood of effective organizational change. This practical viewpoint is decisively different from the existing discourse-based change studies (Barrett et al. 1995; Heracleous and Barrett 2001).

\section{Social constructionism}

This article examines a meta-theory on which discourse-based organizational change relies by considering the nature of social constructionism, which has a significant impact on the narratives of the field (Bushe and Marshak 2015; Barrett 2015; Cooperrider et al. 1995). Based on Berger and Luckmann's (1966) fundamental idea that social reality is created by human interaction, Gergen (1985, pp 266-268) summarizes the following four critical premises of social constructionism: (a) what we take to be an experience of the world does not in itself dictate the terms by which the world is understood, (b) the terms in which the world is understood are social artifacts of historically situated interactions among the people, (c) the degree to which a given form of understanding prevails or is sustained across time is fundamentally dependent on the vicissitudes of social processes and not on the empirical validity of the perspective in question, and (d) forms of negotiated understanding are critical in social life because they are integral to many other activities in which people engage.

Given the Japanese characteristics summarized in the previous sub-section, it can be assumed that social constructionism has a good fit with some aspects of Japanese organizational culture. Specifically, (b) and (d) are reasonably similar to those of the Japanese culture of high-context communication (meanings are social constructs of the interactions and depend on the context/history). Another possibility, however, is to say that its no-reality/no-solution approach may have potential conflicts with the Japanese "family-tie orientation" culture, which leads members to regard their authority figure's judgments as concrete solutions (Keys and Miller 1984; Tanaka 1981).

\section{Sense-censoring and strategic ination (political sensemaking approach)}

It may also be worth extending the discourse-based perspective to an interpretivist approach to the political process of organizational communication. In this respect, it is critical to consider two recent studies in international management studies.

Clark and Geppert (2011) have focused on a political sensemaking approach ${ }^{2}$ to the post-acquisition integration process, directing attention to how powerfully social actors construct the relationship between multinational corporations and their

\footnotetext{
${ }^{2}$ Sensemaking is one of the core concepts in the interpretivist approach and is defined as the recurring cycle of communication through which people create and maintain an intersubjective world. It is also "understood as a process that is (a) grounded in identity construction, (b) retrospective, (c) enactive of sensible environments, (d) social, (e) ongoing, (f) focused on and by extracted cues, (g) driven by plausibility rather than accuracy" (Weick 1995, p 17).
} 
Table 1 Japanese cultural beliefs in organizations

1. Avoiding confrontation and disruption is appropriate behavior to sustain a good relationship at the workplace

2. Saving face by avoiding shame and being demeaning in public talk is highly prioritized

3. An authority figure always decides what is right; the authoritarian pressure leads members to hide or restrict their judgments

4. Gradual and continuous development of organizations and human resources is traditionally valuable

multiple local contexts. Their model identifies a broad set of conditions under which the new way of thinking about subsidiary integration is developed by focusing on the processes of identity reconstruction and institution building.

Whittle et al. (2016) developed Clark and Geppert's (2011) political sensemaking approach and studied a mechanism of political processes between the headquarters of an American multinational corporation and their subsidiary in Britain. Adding to the existing body of sensemaking-related constructs (Maitlis and Christianson 2014), they define sense-censoring as "the process through which actors consciously 'censor' their sensemaking accounts, with or without the presence of any official attempts to edit or silence them, due to anticipated reactions or counter-actions" (Whittle et al. 2016, p 1324). Sensemaking about power and politics, thereby, leads to sense-censoring (saying nothing) and may cause strategic inaction (doing nothing) that allows the crisis to mushroom and ultimately ends up costing the firm hundreds of millions of dollars and significant reputational damage.

\section{The fit between Japanese organizational culture and discourse-based change}

From the literature introduced in the previous section, combined with a more practical interpretation of leadership in Japan (Nagaishi 2020), this article attempts to extract the following four aspects of Japanese organizational culture (Table 1):

- (JOC1) Avoiding confrontation and disruption is an appropriate behavior to sustain a good relationship at the workplace (Hamaguchi 1982; Nagaishi 2020).

- (JOC2) Saving face by avoiding shame and being demeaning in public talk is highly prioritized (Aslani et al. 2016; Keys and Miller 1984; Tanaka 1981).

- (JOC3) An authority figure always decides what is right; the authoritarian pressure leads members to hide or restrict their judgments (Keys and Miller 1984; Nagaishi 2020; Tanaka 1981).

- (JOC4) The Japanese orientation toward intimacy and family ties leads to a collectivistic long-term perspective of respecting the gradual and continuous development of organizations and human resources (Marshak 1993a; Nagaishi 2020; Teranishi 2018). 


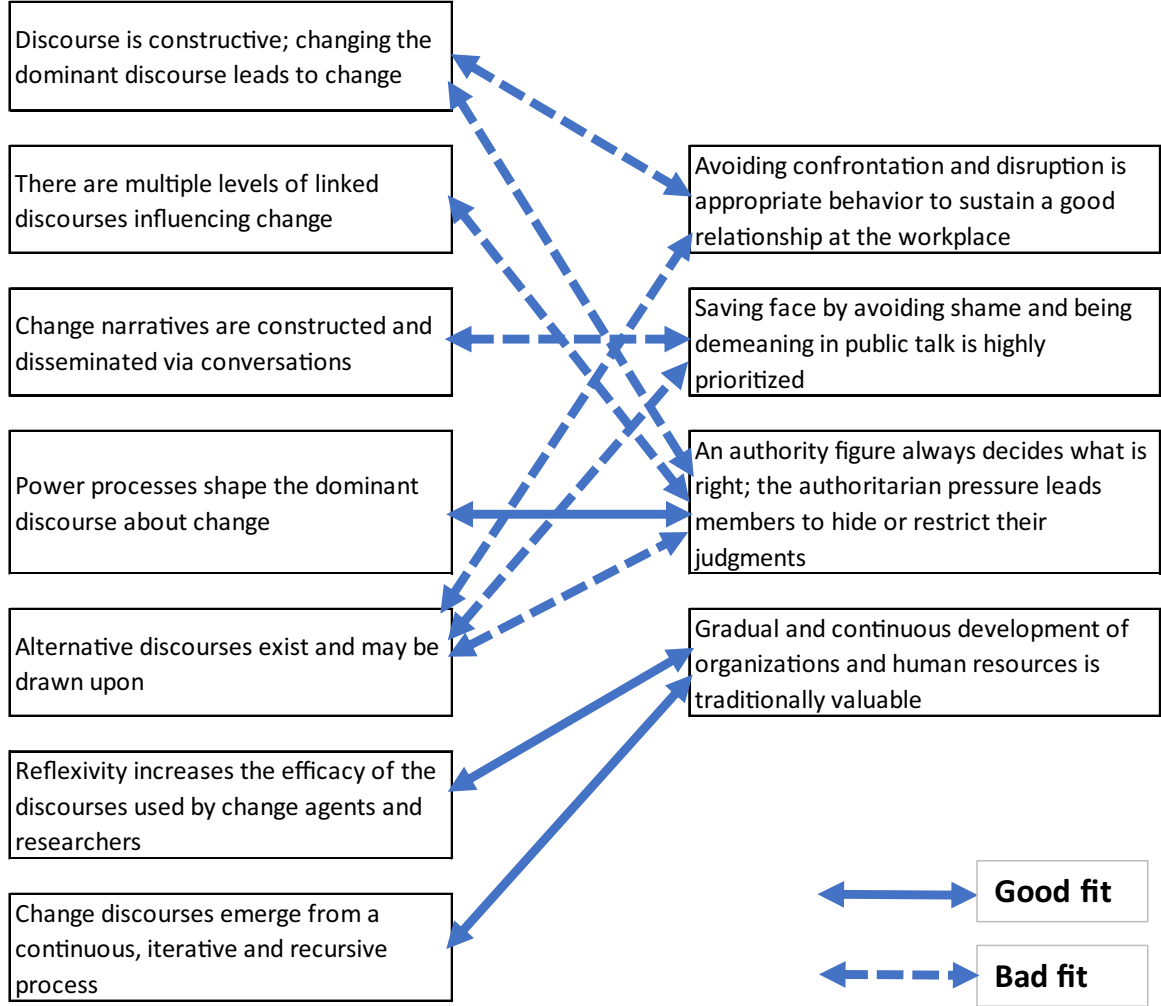

Fig. 1 Discourse-based change assumptions and Japanese culture

These four cultural aspects are reasonably compatible with Hofstede's (1980, 2001) cultural evaluation of Japan, which includes high power distance (that can cause JOC3), high uncertainty avoidance (JOC1 and JOC2), high collectivism (JOC1 and JOC4), and high long-term orientation (JOC4).

Figure 1 summarizes the overall fit between the discourse-based change assumptions (DOC1-7) and Japanese organizational culture (JOC1-4). As depicted in the figure, it seems reasonable for the author to conclude that the results are mixed; there are some good fits and some bad fits.

For example, on the one hand, the figure clearly illustrates that Japanese collectivistic long-term perspective to respect gradual and continuous development of organizations and human resources (JOC4) has a good fit with discourse-based change assumptions of the recursive change process based on reflexivity (DOC6-7). In the literature on the organizational structure of MNEs, there is fairly a general agreement on the point that Japanese firms share certain collectivistic long-term perspectives, as opposed to the individualistic and short-term ones of Anglo-Saxon firms; one of the differences in the literature is whether they deal with the historical 
and cultural factors explicitly (Itagaki 1997; Nagaishi 2014) or not (Kojima 1978; Caves 1982). Such a collectivistic long-term perspective of Japanese organizations, combined with the impacts of the Confucian philosophy (Marshak 1993a) and the Buddhist religious foundation (Teranishi 2018), seems a good match for the viewpoint of the discourse-based change mindset that advocates continuous and adaptive nature of reframing organizational communication with multiple discursive changes occurring at various levels and speeds.

On the other hand, it also highlights that the Japanese may not easily buy in the importance of changing the dominant discourse with welcoming multiple/alternative discourses (DOC1, 2, 5) due to their hidden assumptions like "the boss has an authority to decide what is right" (JOC3). This finding implies that the discoursebased interpretivist perspective does not match Japanese authoritarian orientation in which "an authority figure as a definite decision-maker" is a sticky premise, and the pressure leads members to hide or restrict their judgments.

Although much work remains to be done, the preliminary results from the above analysis indicate an overall mixed fit between the discourse-based change assumptions and Japanese organizational culture. In particular, while the Japanese cultural brief to respect gradual and continuous process development has good potential to fit the reflexive and recursive nature of discourse-based change, the discursive belief (i.e., making change happen by changing the dominant discourse) has a bad fit with the Japanese orientation to strong hierarchies and authoritarian leadership. Besides, given the Japanese inclination to saving face by avoiding shame and being demeaning in public talk (this tendency may be a rational response to Japanese authoritarian culture), it is plausible to assume that surfacing alternative discourses in organizations is always a risky option for all members.

Here are two critical questions for change agents practicing within Japanese organizational culture. First, who are the most influential actors in shaping dominant discourse, and what are the sources of their influence? Second, given the Japanese authoritarian orientation, how can change practitioners identify and use alternative discourses at multiple levels to support change processes? These questions for change practice are intertwined with the research questions introduced in the next section.

\section{Methodology and research questions}

The author was invited into the company to act as an 'action researcher' to provide his (unremunerated) assistance in two Japanese companies' strategic change initiatives, in return for being permitted to collect data for academic purposes. He tried to illuminate how discursive methods could advance organizational change research in a particular cultural setting, i.e., Japanese companies. In particular, the studies highlighted the stories on who was the most influential in shaping discourses and what were the sources and consequences of their influence.

The author focuses on two things in the case studies: (a) power process and (b) possibility for alternative discourse. The first originates from the question in the previous section, i.e., who are the most influential in shaping dominant discourse and 
Table 2 Questions for researchers and practitioners

\begin{tabular}{|c|c|c|}
\hline Focus & Questions for researchers & Questions for practitioners \\
\hline Power process & $\begin{array}{l}\text { RQ1: What are culture-specific dominant } \\
\text { discourses in Japanese companies, and } \\
\text { what are the processes that make them } \\
\text { established and maintained? }\end{array}$ & $\begin{array}{l}\text { PQ1: Who are the actors who } \\
\text { will be most influential to shape } \\
\text { dominant discourse? What are } \\
\text { the sources of their influence? }\end{array}$ \\
\hline $\begin{array}{l}\text { Possibility for alterna- } \\
\text { tive discourse }\end{array}$ & $\begin{array}{l}\text { RQ2: What are the sources of alternative } \\
\text { discourses, and what are the processes } \\
\text { that make them sustained despite a } \\
\text { solid authoritarian culture? }\end{array}$ & $\begin{array}{l}\text { PQ2: How can we identify and use } \\
\text { alternative discourses that may } \\
\text { exist at multiple levels to support } \\
\text { change processes? }\end{array}$ \\
\hline
\end{tabular}

what kind of power/authority they have in Japanese organizational culture. It directly follows Grant and Marshak's (2011) DOC4 premise ("power processes shape the dominant discourse about change"). The second is closely related to the author's call in the previous section to inquire how change practitioners can identify and use alternative discourses, which may reflect Grant and Marshak's (2011) DOC5 premise ("alternative discourses exist and may be drawn upon").

Following Blaikie and Priest's (2019) research design formulation, the practical questions above invite this article's theoretical speculations for research (Table 2):

- (RQ1) What are culture-specific dominant discourses in Japanese companies, and what are the processes that make them established and maintained?

- (RQ2) What are the sources of alternative discourses, and what are the processes that make them sustained despite a solid authoritarian culture?

Based on Grant and Marshak's (2011) conceptual framework, these are the central research questions that need to be explored to inquire about the successful process of facilitating organizational change by changing dominant discourses. Comparing Japanese organizations in the two different cases allows a consideration of the degree to which differences in leadership and other management factors influence the consequences, even within relatively similar cultural settings.

The present study could be named an interpretative case study based upon an abductive approach in combination with feasible explanations grounded on the rigorous data collected from the author's action research. Peirce (1931) describes what people do when they reason, meaning that logical reasoning has been formulated as deductive, inductive, and abductive. Deductive reasoning allows for reaching a generalizable conclusion based on the logical implications of asserted propositions, whereas inductive reasoning utilizes available observations to develop a theory (Behfar and Okhuysen 2018; Folger and Stein 2017; Helfat 2007).

The process of abduction is a different form of reasoning from deduction and induction. Abductive reasoning takes a set of observations as input and draws suitable "first suggestions" (Bamberger 2019, p 103) of plausible links and explanations. As Peirce points out, "deduction proves that something must be; induction shows that something actually is operative; abduction merely suggests that something may 
$b e$ " (Peirce 1931, p 106). ODC researchers have been traditionally attentive to the process of abductive reasoning that develops knowledge from their experiences (Coghlan 2020; Dunne and Dougherty 2016; Shani et al. 2020). The present study largely follows the processes in many previous ODC studies using abductive reasoning to develop first suggestions from the observed data.

\section{Case study}

The author presents two examples from his action research experiences in Japan. Unless otherwise stated, all names are pseudonyms in the examples. All quotations from the cases are translated from Japanese.

\section{First case}

\section{Outline of the case}

One of the author's clients is the CEO of a small family business in the education industry in Japan. This business included a swimming school that suffered from financial issues due to the declining numbers of students. The client wanted to change the school's business model for financial progress. He wanted to change the training culture in the school from "our training is professional but too hard for usual students" to "our function is to entertain students." He asked the author to provide process consultation ${ }^{3}$ in several meetings in which he wanted to share information with his 12 employees (swimming coaches) about the importance of change in the business concept to survive in the industry. The CEO announced the new concept to the employees, "Great Customer Experiences like Tokyo Disneyland," and wanted to ensure that the employees correctly understood the concept.

In the first meeting, the swimming coaches easily echoed and accepted the new concept (Great Customer Experiences like Tokyo Disneyland). Soon, the results of an "employee work motivation survey" were provided to the CEO (the survey was a periodic diagnosis and the author was not in charge of it). The main findings were the deterioration of the morale of swimming coaches and their disengagement. The CEO was seriously disappointed with the data.

After digesting the survey results, the author had a long conversation with the CEO to check out his experiences and intentions about the next steps. The author was tasked with data collection regarding what was really going on in the minds of the coaches. Accordingly, the author proposed one-on-one interviews with the swimming coaches (the author being the interviewer) and suggested he would find

\footnotetext{
3 As Edger Schein (1999) points out, the most critical function of process consultation is to make visible what is invisible. In general, however, Japanese high-context communication and family-tie orientation result in system members keeping invisible processes even more deeply invisible; members should deduce the proper context without challenging an authority figure (Nagaishi 2020). It can be quite difficult for the members of a Japanese team or organization to diagnose their taken-for-granted cultural assumptions and realize the hidden possibilities and opportunities that may come from engagement and inquiry.
} 
Table 3 Interview excerpts (first case)

\begin{tabular}{|c|c|}
\hline Coach B & $\begin{array}{l}\text { "All students are different. What I want to do is to provide a customized service depending on } \\
\text { their needs and abilities. I don't think 'Great Customer Experiences like Tokyo Disneyland' } \\
\text { is the one and only need of our students." }\end{array}$ \\
\hline Coach C & "The CEO is deciding everything. I know he doesn't want to listen to our opinions." \\
\hline Coach D & $\begin{array}{l}\text { the process to decide the concept. I believe we are able to find out } \\
\text { which we are motivated." }\end{array}$ \\
\hline Coach E & $\begin{array}{l}\text { "I simply don't want to do any new thing. I understand that what the CEO wants to do is a } \\
\text { hopeful direction, but I am too old to learn something new here." }\end{array}$ \\
\hline
\end{tabular}

implications from the analysis on the discourses of the interview data (Phillips and Hardy 2002). The CEO agreed with it.

When the output of the analysis was reported to the CEO, he looked surprised and said, "Until now, I haven't realized anything about the different stories that each swimming coach is making sense from my directions and metaphors. I should change my conversations and language. It will be a gradual change, but I think I should go forward as much as I can." After that, the author supported the organization with one-on-one coaching and process consultation in its critical meeting for about 3 years. Toward the end of the engagement to the process, the author realized that the CEO's narrative had gradually changed to welcoming employees' participation and taking risks to challenge something anew.

\section{Interpretations}

The excerpts from the interview data are shown in Table 3. The data indicates that some members see multiple sources of help and leadership necessary for the change process. They also feel that their participation is denied by the power and control of the CEO. As Morgan (2001, p 85) asserts, "If a managerial change ideology is imposed, the result may be the unnecessary suppression of interests, opinions, or discourses that fall outside of the dominant agenda. When this happens, an environment of 'discursive closure' forms in which alternative voices are silenced."

Marshak (1993b) points out that leaders' metaphors of change can confuse and mislead members when they do not match the actual intended change. His argument suggests that the swimming coaches might have been confused and misled when the CEO used metaphors (not radical change but developmental one, e.g., "The change is a piece of cake for all of you. Both swimming school and Tokyo Disneyland are creating service-based customer experiences") about the change effort that do not match the actual intention (transformation). Another possibility to be considered is whether the swimming coaches have their self-images as professional teachers, who are more highly valued in Japanese society than entertainers (the interview data from Coach B above implies this possibility). 


\section{Second case}

\section{Outline of the case}

The author was asked to support the start-up of a cross-functional project team of a large Japanese company. The group consisted of 26 members (junior-manager class, age: 30-35 years) chosen by two vice presidents (VPs). One of the author's sponsors was directly in charge of the project, and the other one was the VP of human resources of the corporate headquarters. They were chosen as candidates of team members to launch a new start-up that was a wholly owned subsidiary of the Japanese company but free from the company's traditional command-and-control management style and a symbolic project of the company's transformational challenges.

The author began with one-on-one interviews with all the 26 members and the two VPs of the company and attempted to confirm the authenticity of their willingness to engage in the process. They all seemed to commit to seeking their hopeful future in a complex and unpredictable journey. The author felt that the readiness of the client's system was sufficient to convene an adaptive inquiry. He also shared his view with the VPs that the journey was an adaptive and a complex challenge in which multiple sources of help and leadership were necessary to achieve the end goal (to be a symbolic project of the company's transformational challenges), and unhelpful power and control would be addressed by making them visible (Corrigan 2015). The author invited the members and VPs to a 2-day workshop at a local hotel, 200 miles away from the headquarters. At the beginning of the event, he found out that the members of the system were anxious and that most of them, similar to other Japanese ODC cases, were quiet, cautious, and trying to figure out the proper behavior before speaking. To unlock normally unspoken sentiments and activate their commitment to the project, the author implemented a metaphoric intervention ${ }^{4}$ by asking all the 26 members to complete a statement, which is similar to the one available in the literature (Smith and Eisenberg 1987; Morgan 2001): "Being a manager at the company is like ....." which was intended to extract metaphorical responses from them. The similes and metaphors revealed by the 25 members were safe ones like "being a great captain," "a good marathon coach," etc. They did not challenge the prevailing narratives of the company. However, one member, KS (his initials), who was a sales manager, wrote: "a slave of my clients (and that's what I hate)."

The VP (HR) immediately interrupted and shouted: "What do you mean by the words slave and hate, KS? Are you not with us? If you want to go home, OK, go home now!" Some members followed this conversation and said: "I cannot

\footnotetext{
${ }^{4}$ Metaphoric intervention is a hopeful option for extracting metaphorical responses from the clients to reveal the existence of multiple realities within the system (Barrett and Cooperrider 1990; Marshak 1993b; Morgan 2001). Given the observation that the Japanese tend to prefer indirect communication, a metaphoric intervention can be an effective option that makes unlocking hidden processes and creating clients' psychological safety compatible. By nature, metaphors are indirect, and the Japanese are good at catching the hidden context of such indirect communications. For example, in a meeting at the workplace, the utterance "I don't get the purpose of this session" is generally not the proper behavior and thus rarely chosen in Japan. However, revealing a metaphor such as "our meeting is a kind of sailing without a compass" in an off-site workshop can be acceptable for the usual Japanese.
} 
understand what KS means. Please clarify what is the bottom line of your words." Some said: "I do understand what KS said. I am also a slave of my clients who doesn't have any freedom about my job."

The sponsor VP said to me: "This is not what I want. We should move to our bottom line." The author said to him: "I told you, at the beginning of this project, that unhelpful power and control would be addressed by making it visible. I observe now that your control at this moment seems to be too much and somewhat unhelpful. What do you think?" He did not say anything. There were 2 or 3 min of complete silence in the space. Then the author said to the sponsor VP, "I think this is the bottom line. For a moment, let us hold this messy situation that can break apart the dominant culture of this organization." He said, "Makoto, you are right. I agreed with you about the importance of sharing leadership and power in our journey at the very beginning of this project. I am OK to stay with this mess and am willing to support all the members here."

The author focused on holding the space that could support counter-cultural interactions inviting a diversity of the arguments, surfacing differences, and then asking some possibility-oriented questions to allow for an emerging coherence and a collective will of the team (Holman 2015). After 2 days of long discussions, they got through the disruption and found a vision, "amazing experiences based on equal partnership principle between customers and all of us," in their new business. The shared vision guided them to an innovative business model. Recently, the author met KS and asked him: "Tell me why you could put that evocative (and seemingly risky) metaphor at that time?" He answered, "Because I believed in your way of being in the space. From your being there, I sensed you were not a 'slave' of the VPs there and decided to attempt things I had never done."

\section{Interpretations}

The excerpts of the conversations in the 2-day workshop are shown in Table 4. In Japan, authoritarian pressure (which leads members to hide or restrict their judgments) may influence members to further hide the hidden processes. Then, negative sensemaking about the ongoing process and the anxieties of members often prevail in a space (Bushe 2009; Marshak 2016). Schein (2013) pointed out that there are two types of anxiety for change. One is 'survival anxiety' that stems from the horrible realization that someone has to change to survive (i.e., threatening workers with loss of jobs or valued rewards). The other is called 'learning anxiety' that comes from being afraid to change for fear of failure. In the second case, the junior manager (KS) might have used the metaphor ("slave of my clients") stimulated by his survival anxiety overcoming his learning anxiety. In the recent conversation with the author, the junior manager confessed his survival anxiety was so high that he was seriously thinking about resigning just before the workshop. In the first case ("Great Customer Experiences like Tokyo Disneyland"), some interview data (especially, what Coach E said) supports the hypothesis that the swimming coaches did not speak up due to their intense learning anxiety (for them, it might be more significant than their survival anxiety). 
Table 4 Excerpts of conversations (second case)

\begin{tabular}{ll}
\hline VP, HR & "What do you mean by the words slave and hate, KS? Are you not with us? If \\
& you want to go home, OK, go home now!" \\
YY (Project Member) & "I do understand what KS said. I am also a slave of my clients who doesn't have \\
any freedom about my job." \\
"This is not what I want. We should move to our bottom line." \\
Sponsor VP & "I think this is the bottom line. For a moment, let us hold this messy situation \\
Consultant & that can break apart the dominant culture of this organization." \\
"I agreed with you about the importance of sharing leadership and power in our \\
journey at the very beginning of this project. I am OK to stay with this mess \\
and am willing to support all the members here." \\
KS (Project Member) & "Because I believed in your way of being in the space. From your being there, I \\
& sensed you were not a 'slave' of the VPs there and decided to attempt things I \\
had never done"
\end{tabular}

Given that the Japanese tend to prefer indirect communication, hosting off-site workshops for metaphoric intervention can be an effective option to unlock hidden processes and create clients' psychological safety. The author puts forth a more profound question in this context, i.e., "what conditions need to be present for a metaphor to be safely or effectively disruptive in Japan?" Although the question is too involved to treat here in detail, one of the crucial factors seems to be, as Marshak and Heracleous (2018) suggested, the balance between evocative (i.e., guiding cognitive reconstruction) and instructive (i.e., realistic from the viewpoint of job instruction) natures of metaphors. For example, in the first case of this article, the concept "Great Customer Experiences like Tokyo Disneyland" did not work out since it was not supported by the specific day-to-day directions to the swimming coaches (specifically, the interview data from Coach A support this hypothesis).

\section{Discussion and interpretations}

As Grant and Marshak (2011) suggested, discourse-based organizational change has an interpretive and multidimensional nature. It is necessary, at this point, to deal with further discussions and interpretations of the case findings from the viewpoint of discourse analysis. Firstly, the author takes up some data on the actors' conversations and discusses what kind of cultural beliefs and discourse-based assumptions are behind the utterances. Secondly, some implications are suggested for researchers and practitioners in line with the discourse-based questions (both for researchers and practitioners) raised in Table 2.

\section{Further analysis of the data}

Table 5 summarizes data of the actors' conversations, comparing the first case of the small family business with the second case of the start-up project team. The first point to note is that both cases have a common ground that the change efforts face 
a transformational turnaround when the belief of gradual and continuous development of organizations and human resources (JOC4) and the fundamental discursive assumptions (letting the dominant discourses go and welcoming alternative ones leads to change; DOC1, 2, 5) simultaneously support the discourses of change sponsors. This core point is similar to the situations expressed by the CEO (first case) and the sponsor VP (second case) in the midst of the change processes:

(The CEO, first case)

"Until now, I haven't realized anything about the different stories that swimming coaches are making sense from my directions and metaphors. I should change my words and conversations. It will be a gradual change, but I think I should go forward as much as I can."

(The sponsor VP, second case)

"I agreed with you about the importance of sharing leadership and power in our journey at the very beginning of this project. I am OK to stay with this mess and am willing to support all the members here."

Judging from the data, it seems fair to hypothesize a condition under which the generative nature of the change process is realized in Japanese organizational culture. It is to convince change sponsors of the proposition that welcoming alternative discourses (by letting dominant discourses go) leads to the long-term development of the organization and its members. It also has various common elements with the literature on the development criteria of organizations and change practitioners (Bushe 2010; Bushe and Marshak 2016; Bushe and Nagaishi 2018).

Another notable finding is that the "authority figure as a sacred decision-maker" belief (JOC3) may cause strategic inaction when it is combined with the subordinates' hidden alternative judgments (i.e., sense-censoring). Although the author's specification in this context is ad hoc, the finding is consistent with the arguments put forward by Whittle et al. (2016) that sensemaking about power and politics leads to sense-censoring (saying nothing) and end up with strategic inaction (doing nothing).

\section{Implications for researchers}

This study has implications for researchers, specifically exploring the two research questions shown in Table 2: the inquiry into the power processes in which culturespecific dominant discourses are shaped and maintained (RQ1) and the sources of alternative discourses despite a solid authoritarian culture (RQ2). The four-perspective evaluation highlights the implications more vividly. It divides the findings of the present study into two categories: "power process (RQ1)" and "possibility for alternative discourse (RQ2)." It then subdivides them into two different categories: "first case" and "second case" (see Table 6).

Of the four categories, "power process-first case (swimming school)" consists of two significant findings: (1) subordinates made sense that the CEO's discourses were always sacred and dominant in the long history of the small family business, 


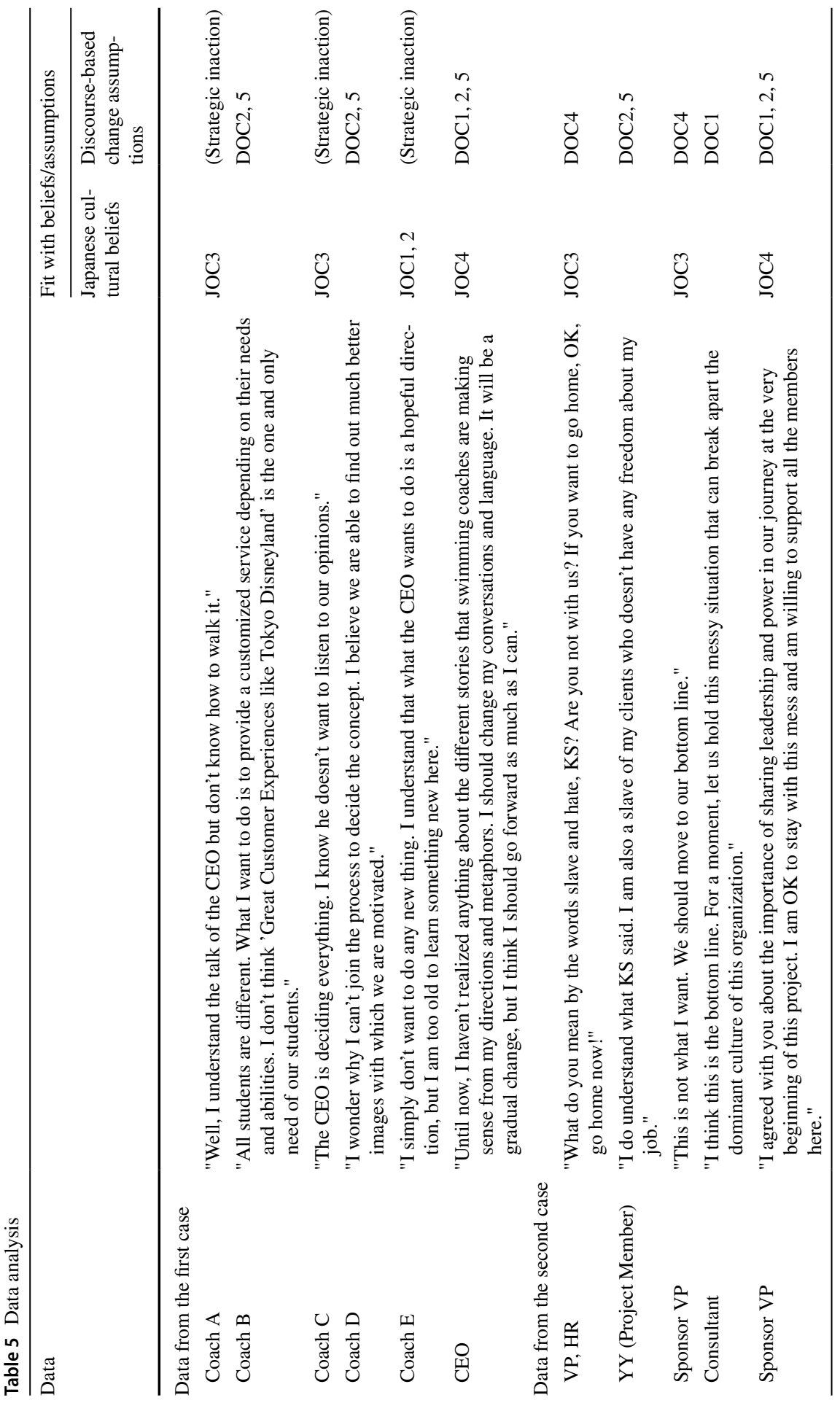

SN Business \& Economics 


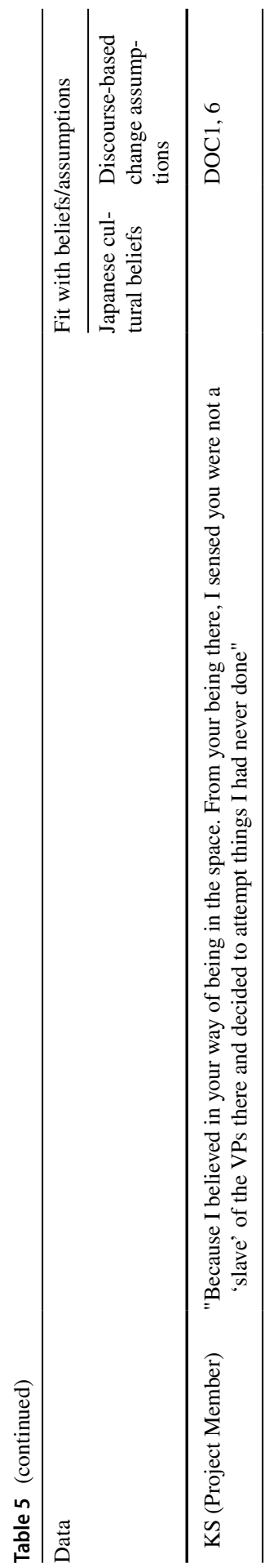


and (2) sensemaking about power dynamics in organizations led to subordinates' sense-censoring (saying nothing) and ended up with strategic inaction (doing nothing). "Power process-second case (start-up project team)" is composed of similar but somewhat different findings: (1) in the large conglomerate, dominant discourses are systematically conveyed and sustained through performance evaluation and the rat race for promotion, and (2) sensemaking about the dominant premises in the existing organizational culture led to most project members' initial sense-censoring (saying nothing). The findings may imply that Japanese organizational control originates from both idolization of authority figures and cultural and institutional education, depending on the available resources of organizations. Besides, the controls often stimulate the processes of sense-censoring (saying nothing), combined with the Japanese cultural orientation to avoiding shame and being demeaning in public talk. The implication cannot be overemphasized in the sense that the political sensemaking approach (e.g.,Clark and Geppert 2011; Whittle et al. 2016) has rich insights on the theoretical development of discourse-based organizational change.

The direction of the following question moves to the emergence of alternative discourses despite a solid authoritarian culture in Japan. "Possibility for alternative discourse-first case (swimming school)" indicates that (1) CEO and some subordinates' survival anxiety, (2) psychological safety during the disruptive process, and (3) trust in the external authority figure's expertise are the primary sources in the case. "Possibility for alternative discourse-second case (start-up project team)," on the other hand, covers (1) talent diversity in the dialogic space, (2) psychological safety during the disruptive process, and (3) trust in the external authority figure's authenticity as the influential factors. These findings illustrate both common grounds and differences between the two cases: while psychological safety and trust in the external authority figure are equally emphasized, the importance of the players' survival anxiety and talent diversity may depend on the case contexts. An abductive explanation is as follows: talent diversity, on the one hand, is highly dependent on the resource availability of organizations, and such a constraint cannot be changed easily. Players' survival anxiety, on the other hand, is less embedded into resource availability and thus can be more sensitive to the organization's and/or the individual's performances. This view is consistent with the literature on organizational path dependence, which reveals the self-reinforcing impact of historical events on the currently available options for organizations (Schreyögg and Sydow 2011; Schreyögg et al. 2011; Sydow et al. 2009).

\section{Implications for practitioners}

The final section deals with the practical questions delineated in Table 2: who are the most influential actors in shaping the dominant discourse and what are the sources of their influence (PQ1)? How can we identify and use alternative discourses that may exist at multiple levels to support change processes (PQ2)?

As far as the first question (PQ1) is concerned, this study preliminarily reveals that it is usually people in the top management (who are often the sponsors of the change initiative) who create dominant discourses through Japanese organizational 


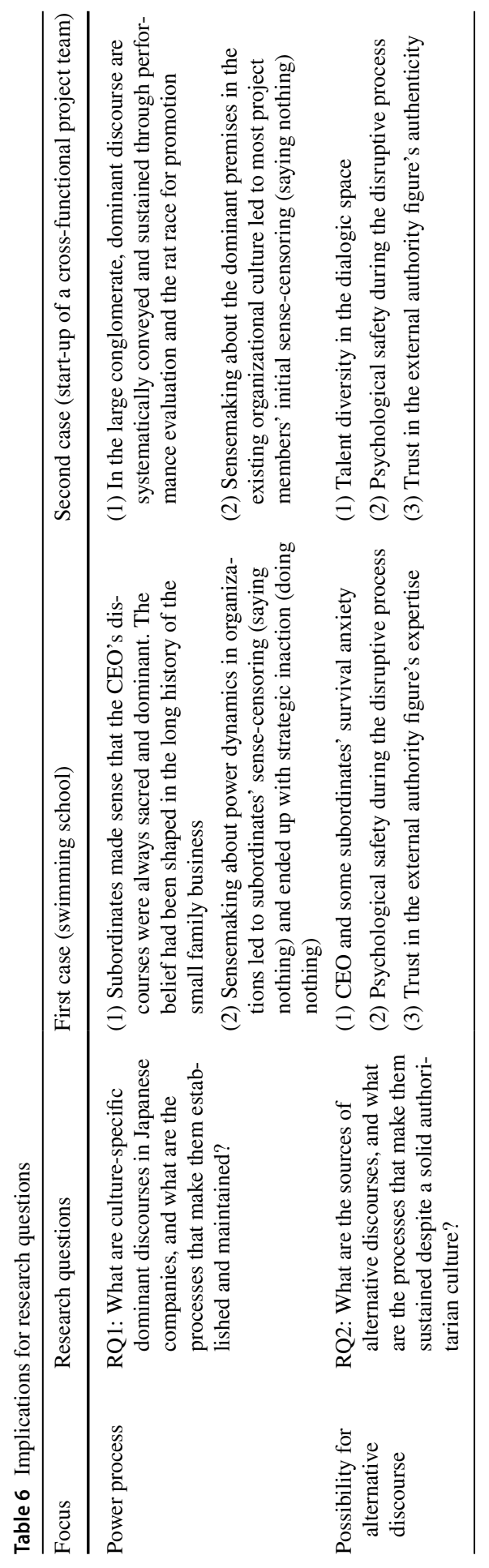

SN Business \& Economics 
control mechanisms, such as idolization of authority figures and cultural/institutional education. Change practitioners may need to identify the sources of the top management's control mechanisms in the client systems and show the hidden aspects of the control to the change sponsors. For example, in the first case (swimming school), the author got interested in historical storytelling (from the ex-CEO, who is the father of the current CEO) about the process in the idolization of authority figures in the family business and showed the current CEO the hidden consequences of the management control (i.e., sense-censoring and strategic inaction) by feeding back the employee interview data.

The second question involves various complex issues. The data of this analysis suggest that the change practitioners invite generative conversations by convincing change sponsors of the proposition that inviting alternative discourses can lead to the long-term development of the organization and its members. However, more essentially, a question is raised in this context, i.e., "how can we convince change sponsors of the proposition?" The author's tentative suggestion is that an external authority figure's "social status" can be a crucial change enabler in Japanese organizations (Battilana 2006; Battilana et al. 2009). Japanese people respect authority and professional skills in organizational life. They often have a shared belief that external consultants have the authority to transplant their respectful professional experiences into client systems (this perception can be a bit different from the roles and responsibilities of a typical ODC consultant in Western culture).

In the second case, it has been interpreted that the author's statement (the sponsor VP's control at that moment was unhelpful) had an impact on turning around the situation since the system members believed that he had an independent authority to speak up in the space. According to Morrison (2014, p 183), "work units develop collective perceptions about the safety and efficacy of voice and that these shared beliefs have an effect on individual voice and silence." It can be, therefore, a hopeful option for change practitioners to reframe the challenging situations as an opportunity to utilize Japanese collective briefs for leveraging generative change. As independent authority figures, external consultants can use themselves as a safety net for system members to take a risk to speak up. Creating culture-specific momentum to change is one of the most critical roles for all change practitioners (Cheung-Judge 2018; Mix 2016).

\section{Conclusion and directions for future research}

This paper has introduced some examples of particular discourse-based organizational change practices in Japanese companies. The investigation suggests that the Japanese authoritarian pressure leads members to shape discourses to hide or restrict their judgments (sense-censoring), combined with the Japanese orientation to avoiding shame and being demeaning in public talk. The findings indicate that the generative change process emerges when change sponsors sympathize with the proposition that changing the dominant discourses and welcoming alternative ones can lead to the long-term development of the organization and its members. So far as the sources of alternative discourses are concerned, 
while psychological safety and trust in the external authority figure are generally required, the importance of the players' survival anxiety and talent diversity may vary across the broad contexts on which organizations depend. The development of the discourse-based change framework with the applications to political sensemaking approach and organizational path dependence is also emphasized.

It can be interpreted that the findings of this study are just the tip of the iceberg in this whole complex inquiry, and it appears meaningful to suggest four unresolved questions for future research. First and foremost, it is interesting to inquire about the conditions under which discourse-based change approaches are more likely to be successful than the other ones in Japan. Given the strong disinclination of the Japanese to deviate from the status quo, it is often the case that the readiness of people (both leaders and followers) to engage in the discursive and the adaptive change process is low at the beginning of the project. It seems, therefore, plausible to assume that supporting clients with a more concrete and predictable change framework (e.g., survey feedback used in the first case of this study) in the early stage of ODC interventions is a meaningful option to consider (Gilpin-Jackson 2013).

Second, one of the limitations of this study is that it could scarcely capture the recursively ongoing nature of change processes in the case analyses. As Grant and Marshak (2011) pointed out, analyzing possible recursive effects of different system levels over the timeframe of the study is one of the main hopeful directions on which the approach to discourse-based change focuses. A more in-depth case analysis with sufficient historical data is left for future research.

Finally, it may be worth integrating this study's insights into organization theory. The framework of discourse-based organizational change may have significant potential to contribute to the development of emerging subjects such as institutional entrepreneurship (Battilana 2006; Battilana et al. 2009; Phillips et al. 2004), with their common assumptions regarding the social construction of discursive processes. Institutional entrepreneurs are change agents who trigger divergent institutional changes and "authors-generators of influential texts that are aimed at influencing the nature and structure of discourses and, in turn, affecting the institutions that are supported by those discourses" (Phillips et al. 2004: 648). Some researchers argue that using rhetorical discourse is a crucial device for institutional entrepreneurs to bring about change in authoritarian organizational culture, although they do not particularly point out "Japanese culture" (Battilana 2006; Suddaby and Greenwood 2005). ODC scholars will develop a unique and comprehensive framework to comprehend how actors can manage the discursive change processes by including such insights from related research traditions.

Acknowledgements A previous version of this paper was presented at the Academy of Management Annual Meeting in August 2020. The author is extremely grateful to the reviewers of the conference paper for their valuable comments.

Funding The author received no financial support for the research, authorship, and/or publication of this article. 


\section{Declarations}

Conflict of interest The author declared no potential conflicts of interest with respect to the research, authorship, and/or publication of this article.

Open Access This article is licensed under a Creative Commons Attribution 4.0 International License, which permits use, sharing, adaptation, distribution and reproduction in any medium or format, as long as you give appropriate credit to the original author(s) and the source, provide a link to the Creative Commons licence, and indicate if changes were made. The images or other third party material in this article are included in the article's Creative Commons licence, unless indicated otherwise in a credit line to the material. If material is not included in the article's Creative Commons licence and your intended use is not permitted by statutory regulation or exceeds the permitted use, you will need to obtain permission directly from the copyright holder. To view a copy of this licence, visit http://creativecommons.org/licen ses/by/4.0/.

\section{References}

Adair W, Buchan NR, Chen X, Liu D (2015) A model of communication context and measure of context dependence. Acad Manag Discov 2(2):198-217

Aslani S, Ramirez-Marin J, Brett J, Yao J, Semnani-Azad Z, Zhang Z, Tinsley C, Weingart L, Adair W (2016) Dignity, face, and honor cultures: a study of negotiation strategy and outcomes in three cultures. J Organ Behav 37(8):1178-1201

Bamberger PA (2019) On the replicability of abductive research in management and organizations: internal replication and its alternatives. Acad Manag Discov 5(2):103-108

Barkema HG, Chen X, George G, Luo Y, Tsui AS (2015) West meets east: new concepts and theories. Acad Manag J 58(2):460-479

Barrett FJ (2015) Social constructionist challenge to representational knowledge: implications for understanding organization change. In: Bushe GR, Marshak RJ (eds) Dialogic organization development: the theory and practice of transformational change. Berrett-Koehler, Oakland, pp 59-76

Barrett FJ, Cooperrider DL (1990) Generative metaphor intervention: a new approach for working with systems divided by conflict and caught in defensive perception. J Appl Behav Sci 26(2):219-239

Barrett FJ, Thomas GF, Hocevar SP (1995) The central role of discourse in largescale change: a social construction perspective. J Appl Behav Sci 31(3):352-372

Battilana J (2006) Agency and institutions: the enabling role of individuals' social position. Organization 13(5):653-676

Battilana J, Leca B, Boxenbaum E (2009) How actors change institutions: towards a theory of institutional entrepreneurship. Acad Manag Ann 3:65-107

Behfar K, Okhuysen GA (2018) Discovery within validation logic: deliberately surfacing, complementing, and substituting abductive reasoning in hypothetico-deductive inquiry. Organ Sci 29(2):323-340

Berger PL, Luckmann T (1966) The social construction of reality: a treatise in the sociology of knowledge. Anchor Books, New York

Blaikie N, Priest J (2019) Designing social research: the logic of anticipation, 3rd edn. Polity Press, Cambridge

Bushe GR (2009) Clear leadership: sustaining real collaboration and partnership at work. Davies-Black, Boston

Bushe GR (2010) Being the container in dialogic OD. Pract Soc Change 1(2):10-15

Bushe GR, Marshak RJ (2015) Dialogic organization development: the theory and practice of transformational change. Berrett-Koehler, Oakland

Bushe GR, Marshak RJ (2016) The dialogic mindset: leading emergent change in a complex world. Organ Dev J 34(1):37-65

Bushe GR, Nagaishi M (2018) Imagining the future through the past: organization development isn't (just) about change. Organ Dev J 36(3):23-36

Caves RE (1982) Multinational enterprises and economic analysis. Cambridge University Press, Cambridge 
Cheung-Judge M (2018) Making value-based decisions and dealing with value dilemma and conflict while working on OD in a global context. In: Jamieson D, Church A, Vogelsang J (eds) Enacting values-based change: organization development in action. Palgrave Macmillan, New York, pp 191-237

Clark E, Geppert M (2011) Subsidiary integration as identity construction and institution building: a political sensemaking approach. J Manage Stud 48(2):395-416

Coghlan D (2020) Edgar Schein on change: insights into the creation of a model. J Appl Behav Sci. https://doi.org/10.1177/0021886320924029

Cooperrider DL, Barrett FJ, Srivastva S (1995) Social construction and appreciative inquiry: a journey in organizational theory. In: Hosking DM, Dachler HP, Gergen KJ (eds) Management and organization: relational alternatives to individualism. Avebury, Aldershot, pp 157-200

Corrigan C (2015) Hosting and holding containers. In: Bushe GR, Marshak RJ (eds) Dialogic organization development: the theory and practice of transformational change. Berrett-Koehler, Oakland, pp 291-304

Doi T (1989) The concept of amae and its psychoanalytic implications. Int Rev Psycho-Anal 16:349-354

Dunne DD, Dougherty D (2016) Abductive reasoning: how innovators navigate in the labyrinth of complex product innovation. Organ Stud 37(2):131-159

Folger R, Stein C (2017) Abduction 101: reasoning processes to aid discovery. Hum Resour Manag Rev 27(2):306-315

Ford JD, Ford LW (1995) The role of conversations in producing intentional change in organizations. Acad Manag Rev 20(3):541-570

Gergen K (1985) Social constructionist movement in modern psychology. Am Psychol 40(3):266-275

Gilpin-Jackson Y (2013) Practicing in the grey area between dialogic and diagnostic organization development: lessons from a healthcare case study. OD Pract 45(1):60-66

Grant D, Marshak RJ (2011) Toward a discourse-centered understanding of organizational change. J Appl Behav Sci 47(2):204-235

Hall ET (1976) Beyond culture. Anchor Books, New York

Hamaguchi E (1982) (in Japanese) Kanjin shugi no shakai Nippon (Japan as a contextual society). ToyoKeizai Shinposha, Tokyo

Helfat CE (2007) Stylized facts, empirical research and theory development in management. Strateg Organ 5(2):185-192

Heracleous L, Barrett M (2001) Organizational change as discourse: communicative actions and deep structures in the context of information technology implementation. Acad Manag J 44(5):755-778

Hofstede G (1980) Motivation, leadership, and organization: do American theories apply abroad? Organ Dyn 9(4):42-63

Hofstede G (2001) Culture's consequences: comparing values, behaviors, institutions, and organizations across nations, 2nd edn. Sage Publications, Thousand Oaks

Hofstede G, Bond MH (1988) The Confucius connection: from cultural roots to economic growth. Organ Dyn 16(4):5-21

Holman P (2015) Complexity, self-organization, and emergence. In: Bushe GR, Marshak RJ (eds) Dialogic organization development: the theory and practice of transformational change. Berrett-Koehler, Oakland, pp 123-149

Hsu FLK (1963) Clan, caste and club. Princeton, Van Nostra

Hsu FLK (1971) Psychological homeostasis and jen: conceptual tools for advancing psychological anthropology. Am Anthropol 73(1):23-44

Itagaki H (1997) Japanese production system. Macmillan, London

Jaeger A (1986) Organization development and national culture: where's the fit? Acad Manag Rev 11(1):178-190

Keys JB, Miller TR (1984) The Japanese management theory jungle. Acad Manag Rev 9(2):342-353

Kojima K (1978) Direct foreign investment: a Japanese model of multinational business operations. Croom Helm, London

LaCour D (2016) Face to face: four light-bulb moments for non-verbal cross-cultural engagement. OD Pract 48(3):65-66

Maitlis S, Christianson M (2014) Sensemaking in organizations: taking stock and moving forward. Acad Manag Ann 8:57-125

Marshak RJ (1993a) Lewin meets Confucius: a re-view of the OD model of change. J Appl Behav Sci 29(4):393-415

Marshak RJ (1993b) Managing the metaphors of change. Organ Dyn 22(1):44-56 
Marshak RJ (2016) Anxiety and change in contemporary organization development. OD Pract 48(1):11-19

Marshak RJ, Grant D (2008) Organizational discourse and new OD practices. Br J Manag 19(1):S7-S19

Marshak RJ, Heracleous L (2018) Language and organizational agility in practice. In: Prange C, Heracleous L (eds) Agility. X: how organizations thrive in unpredictable times. Cambridge University Press, Cambridge, pp 197-205

Marshak RJ, Keenoy T, Oswick C, Grant D (2000) From outer words to inner worlds. J Appl Behav Sci 36(2):245-258

Meyer E (2014) The culture map: breaking through the invisible boundaries of global business. Public Affairs, New York

Mix P (2016) Doing OD work in unfamiliar cultures: what I have learned. OD Pract 48(3):48-56

Morgan JM (2001) Are we 'out of the box' yet? A case study and critique of managerial metaphors of change. Commun Stud 52(1):85-102

Morrison EW (2014) Employee voice and silence. Annu Rev Organ Psych Organ Behav 1(1):173-197

Nagaishi M (2014) Corporate culture of multinational enterprises: an analytical approach. Eihosha, Tokyo

Nagaishi M (2020) Diagnostic and dialogic organization development assumptions: their fit with Japanese culture. Organ Dev J 38(3):33-44

Ouchi WG (1981) Theory Z: how American business can meet the Japanese challenge. Addison-Wesley, Reading

Peirce CS (1931) Pragmatism and pragmaticism. In: Hartshorne C, Weiss P (eds) Collected papers of Charles Sanders Peirce, vol 5. Harvard University Press, Cambridge

Phillips N, Hardy C (2002) Discourse analysis: investigating processes of social construction. Sage Publications, Thousand Oaks

Phillips N, Lawrence TB, Hardy C (2004) Discourse and institutions. Acad Manag Rev 29(4):635-652

Schein EH (1999) Process consultation revisited: building the helping relationship. Addison-Wesley, Reading

Schein EH (2013) Humble inquiry: the gentle art of asking instead of telling. Berrett-Koehler, San Francisco

Schreyögg G, Sydow J (2011) Organizational path dependence: a process view. Organ Stud 32(3):321-335

Schreyögg G, Sydow J, Holtmann P (2011) How history matters in organizations: the case of path dependence. Manag Organ Hist 6:81-100

Shani AB, Coghlan D, Alexander BN (2020) Rediscovering abductive reasoning in organization development and change research. J Appl Behav Sci 56(1):60-72

Smith RC, Eisenberg EM (1987) Conflict at Disneyland: a root-metaphor analysis. Commun Monogr 54(4):367-380

Suddaby R, Greenwood R (2005) Rhetorical strategies of legitimacy. Adm Sci Q 50(1):35-67

Sydow J, Schreyögg G, Koch J (2009) Organizational path dependence: opening the black box. Acad Manag Rev 34(4):689-709

Szkudlarek B, Osland JS, Nardon L, Zander L (2020) Communication and culture in international business: moving the field forward. J World Bus 55(6):101126

Tanaka FJ (1981) Lifetime employment in Japan. Challenge 24(3):23-29

Teranishi J (2018) (in Japanese) Nihon gata shihonshugi: sono seishin no minamoto (Japanese capitalism: its religious foundations). Chuko Shinsho, Tokyo

Trompenaars F, Woolliams P (2003) Business across cultures. Capstone, Chichester

Weick KE (1995) Sensemaking in organizations. Sage Publications, Thousand Oaks

Whittle A, Mueller F, Gilchrist A, Lenney P (2016) Sensemaking, sense-censoring and strategic inaction: the discursive enactment of power and politics in a multinational corporation. Organ Stud 37(9):1323-1351 